\title{
EXPERIMENTAL RESULTS AND DYNAMIC PARAMETERS FOR THE PENGUIN VIBRATION DAMPER (PVD) FOR WIND AND EARTHQUAKE LOADING
}

\author{
M.D. Monti ${ }^{1,3}$, J.X. Zhao ${ }^{2,3}$, C.R. Gannon ${ }^{1}$ and W.H. Robinson ${ }^{1,3}$
}

\begin{abstract}
SUMMARY
Penguin Engineering Ltd has developed a compact, efficient, hysteretic damping device, the Penguin Vibration Damper (PVD). Experimental test results show that the PVD can provide a significant amount of damping at displacements as small as 50 micro-metres.

The hysteresis behaviour of the PVD can be described well either by a model having a linear spring in parallel with a viscous dashpot, or by a bi-linear model, with the parameters of both models being displacement-amplitude dependent. For large displacements, the bi-linear model gives an accurate representation of the PVD's hysteresis loops, and the parameters for the bi-linear model can be taken as constants. Non-linear models, such as the hyperbolic, Ramberg-Osgood and multi-surface plasticity models, can also be used and have an advantage of displacement-amplitude-independent parameters. However, it can be shown that nonlinear models do not correctly predict the amount of damping that a PVD provides at large displacement even though the equivalent spring coefficient can be well approximated. When the PVDs are expected to undergo large displacements, it is possibly best to use a simple bi-linear model in dynamic nonlinear structural analyses, because the bi-linear model with suitably selected parameters can produce the correct amount of damping derived from the experimental data.
\end{abstract}

The changes of the PVD's dynamic behaviour are small after a fatigue test of 144000 cycles with a displacement amplitude of $2 \mathrm{~mm}$.

An analysis of a 6-storey reinforced concrete moment resisting frame is used to demonstrate the effect of the damper. Equivalent first modal damping ratios are estimated for various levels of earthquake excitations. The example shows that the dampers can provide a large amount of damping to the structure and enhance the structural capacity, for resisting earthquakes, by $50-100 \%$.

\section{INTRODUCTION}

Lead-based damping devices, such as lead rubber bearings and lead extrusion dampers, have been used successfully as seismic protection devices in many countries to counter the effects of earthquakes on structures [1-4]. This technology, originally invented in New Zealand by Robinson [1-4] at the DSIR Physics and Engineering Laboratory, has grown over the last twenty-seven years to become one of the most versatile damping systems. Many seismic isolation devices using lead have been installed in several hundred structures throughout the world [1].

For many structures with long fundamental periods of vibration, such as tall buildings, providing earthquake protection through the seismic isolation is either not practical or not economical. Penguin Engineering Ltd has developed a lead-shear damper [5] which reduces both large and small structural motions by providing 'added damping'. This damper can be used to damp the small and persistent vibrations encountered in the wind response of flexible tall structures, whilst also reducing the large deflections associated with earthquake motion.

The Penguin Vibration Damper (PVD), is a compact damping device that can provide a significant amount of hysteretic damping at displacements as low as \pm 50 micro-metres $[6,7]$. 'Added damping' can be provided in a structure by distributing many small capacity devices throughout the structure. Suitable for vibration protection of structures with a wide range of fundamental periods, including those outside the practical range for effective seismic isolation, this approach effectively creates a highly damped structure [8].

The design working displacement range of the $200 \mathrm{kN}$ prototype PVD, for which the experimental results are presented, is from \pm 50 micro-metres to $\pm 10 \mathrm{~mm}$. Larger displacements come with larger devices, but the sensitivity decreases as size increases. For example a $1 \mathrm{MN}$ PVD with a design maximum displacement of $\pm 100 \mathrm{~mm}$ will begin to give appreciable hysteretic damping at $\pm 0.3 \mathrm{~mm}$ [9]. An example of this self-contained damper is pictured in Figure 1.

$1 \quad$ Penguin Engineering Ltd, Lower Hutt

2 Institute of Geological and Nuclear Sciences, Lower Hutt

3 Member 


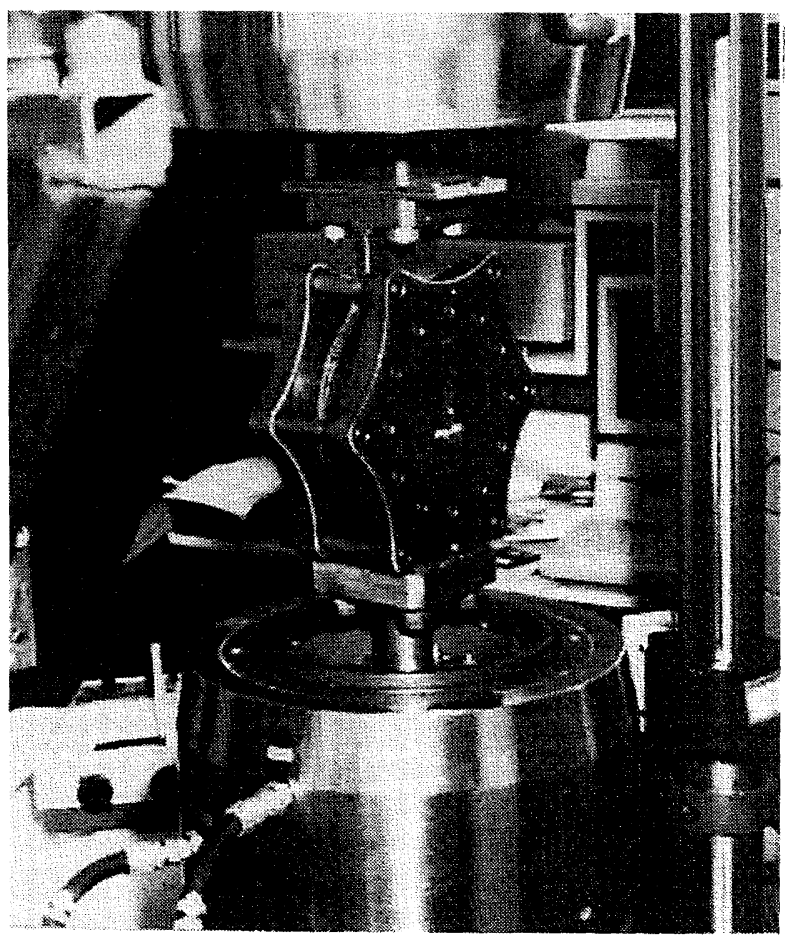

Figure 1: The self-contained Penguin Vibration Damper. Shown is a $200 \mathrm{kN}$ PVD damper with a maximum stroke of $\pm 10 \mathrm{~mm}$.

The damping of the PVD is achieved through the plastic deformation of a lead core. The use of lead enables the PVD to undergo many cycles, dissipating large amounts of energy, while maintaining its mechanical properties. This is achieved through dynamic and meta-dynamic recrystallization of lead as described by Monti et al. [6].

Because the PVD is a hysteretic damper using lead to provide damping, its dynamic properties are virtually independent of excitation frequency and ambient temperature. For example, a PVD installed in a structure will apply an almost constant maximum force to the structural members to which the damper is connected for a very large range of damper displacement and at all likely ambient temperatures. For a particular kind of visco-elastic damper, when the ambient temperature changes from $24^{\circ} \mathrm{C}$ to $36^{\circ} \mathrm{C}$, the change of maximum damper force can be larger than $50 \%$ and the added damping ratio reduces from about $15 \%$ to about $7 \%$, as shown by an experimental study [10]. This indicates that the structural members connected to a visco-elastic damper must be designed for the maximum possible damper forces, while the added damping ratio for the structure must be set at a conservatively small value corresponding to the expected range of ambient temperatures.

Because the PVD uses the plastic deformation of lead to provide damping and lead will virtually not fail under cyclic loading [11], it is unlikely for the PVD to fail by fatigue within the design life of a structure. This is extremely important for reducing vibrations induced by wind. Many other types of hysteretic dampers, for example, steel dampers, have only a limited number of loading cycles before fatigue failure occurs.
The PVD can provide a significant amount of damping at a very small displacement, for example $0.2 \mathrm{~mm}$, which is at least an order of magnitude smaller than the tolerated inter-storey drift for even masonry buildings. This suggests that PVDs can be used to provide damping for flexible structures, such as steel moment-resisting frames, or used to provide significant damping to relatively stiff structures, such as reinforced concrete structures and possibly certain types of masonry structures, in order to limit damage at the maximum design loads.

This device is principally designed to be installed in a location where displacement can be utilized to produce damping, such as in diagonal bracing in a reinforced concrete moment resisting frame building as shown in Figure 2 .

\section{EXPERIMENTATION}

Seven PVDs have been tested for many thousands of cycles at displacement ranging from \pm 1 micro-metre to $\pm 17 \mathrm{~mm}$. The device for which the results are shown here was tested for ten cycles in each of 21 tests at a range of displacements from \pm 1.25 micro-metres to $\pm 5 \mathrm{~mm}$ with a loading frequency of 0.1 $\mathrm{Hz}$. The maximum testing displacement for the damper described here was limited by the loading capacity $(250 \mathrm{kN})$ of the testing machine. The tests were displacement controlled and the displacement amplitude for each test is indicated in Figure 5. The displacement interval for the tests was not regular because the actual damper displacement amplitude is always less than that specified for the test machine (some deformation occurred in the connection between the damper and the test machine). The cycling frequency of $0.1 \mathrm{~Hz}$ was chosen because (1) the damper is most likely to be used in a structure with a long natural period; (2) the dynamic characteristics of a lead-based damper is virtually independent from loading speed [1]; and (3) the loading capacity of the test machine will be reached at a much smaller displacement than the maximum displacement presented in this paper, if a high loading speed is used. A loading speed of $0.5 \mathrm{~Hz}$ was also used for one test to confirm the independence of loading speed for the damper. For displacement up to 10 micro-meters, the damper has an almost elastic linear behaviour. The device was then subjected to 144000 cycles at $\pm 2 \mathrm{~mm}$ before a member of the test machine used failed in fatigue. The 144000 cycles is equivalent to the number of cycles that would be experienced by a PVD installed in a structure subjected to a hurricane blowing constantly for 16 days. The large number of loading cycles indicate that fatigue failure of the damper is unlikely. We intend to test the device for 100 million cycles, which would correspond to a hurricane blowing 24 hours a day for 30 years.

\section{DYNAMIC MODELS FOR PENGUIN VIBRATION DAMPERS}

A PVD installed in a building can be modelled as a non-linear member with its hysteresis loops defined by experimental results. The experimental results show that the PVD can be modelled in a number of ways as described in this section. 


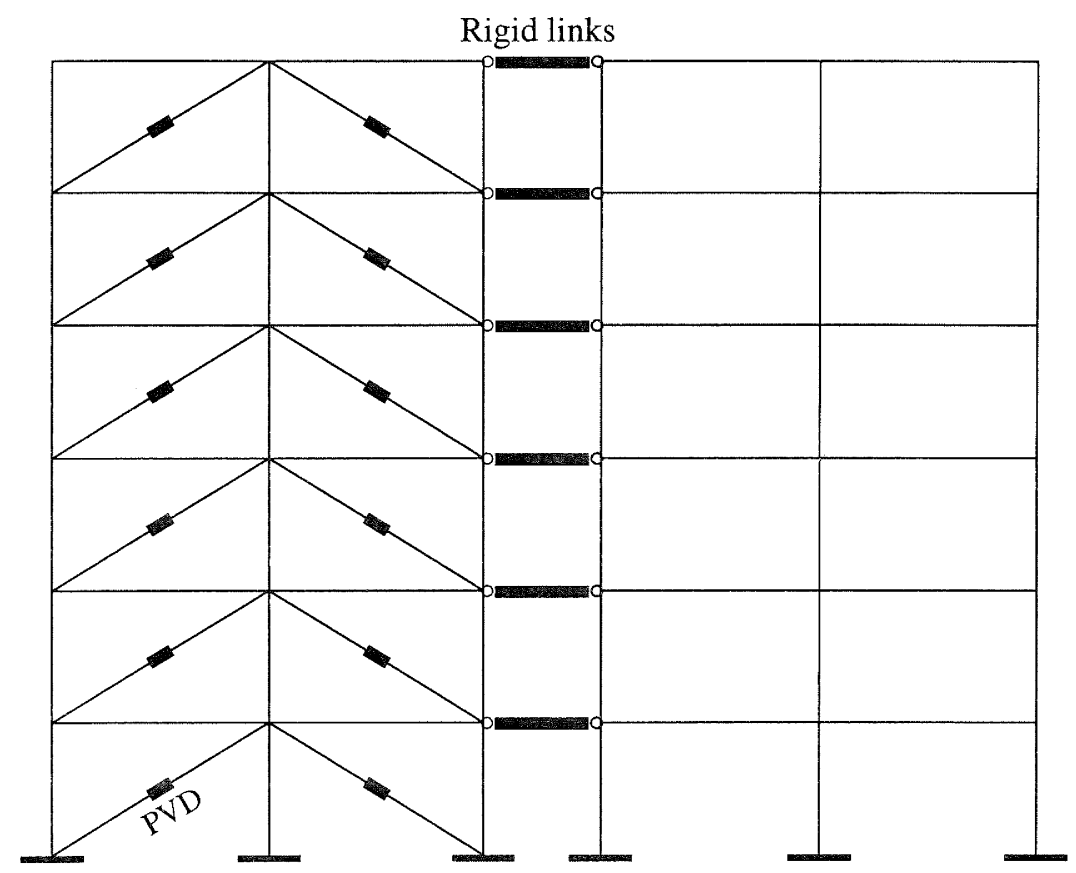

Figure 2: A numerical model for two identical 6-storey reinforced concrete moment resisting frames with PVDs installed in one frame.

A spring and an equivalent viscous damper in parallel with spring coefficient $\mathrm{K}$ and damping coefficient $\mathrm{C}$ being dependent on the maximum damper displacement can be used to model the PVD. This model is potentially useful for initial design, because the maximum inter-storey drift given by a design code or limited by service requirements can be used to decide the amount of damping required and the type and number of dampers required. This model is also important because the variations of the spring and the damping coefficients with damper displacement specify uniquely the hysteresis loops of the damper.

At large displacements, the hysteresis loop of the PVD can be closely approximated by a bi-linear model. This model is appropriate for a structure installed with PVDs under design earthquake loading and extreme wind loading.

The linear spring and damper model and the bi-linear model have displacement-amplitude-dependent parameters and can be used only for approximate structural analyses. Non-linear models, such as the hyperbolic, Ramberg-Osgood and multisurface plasticity models, can be used to describe the non-linear behaviours of the PVD, but care must be taken to ensure that both the stiffness and the equivalent damping ratio of the damper are well approximated.

\section{MODEL PARAMETERS DERIVED FROM EXPERIMENTAL RESULTS}

(a) Linear spring and damper model

Using the method given by Monti et al. [12], the spring coefficient and damping ratio are derived from experimental data. The spring coefficient can be estimated by either of the two methods [12] and the estimates are nearly identical at small displacements. At large displacements, the two spring coefficients $\mathrm{K}$ (the secant stiffness of the model hysteresis loop at the peak displacement) and $\mathrm{K}_{\mathrm{e}}$ (the secant stiffness at the peak load and the peak displacement of the experimental hysteresis loops, see Figure 3c) are very different, with $\mathrm{K}_{\mathrm{e}}$ (given by Skinner et al. [1]) having twice the amplitude of $\mathrm{K}$ derived here. However, the definition of the spring coefficient makes little difference to the dynamic properties of a structure incorporating PVDs, because the spring coefficient of the PVD is likely to be much smaller than the storey lateral stiffness of a building at the operating range of displacements. The load time-history predicted by the model for a particular test and the hysteresis loops of the model are shown in Figure 3.

The equivalent damping ratio (fraction of critical) for a damper can be specified by Equation (2.13) of Skinner et al. [1], and when the damper is undergoing steady-state, i.e. sinusoidal, displacement with radial frequency $\omega$, the equivalent hysteretic damping ratio can be written as

$$
\zeta=\frac{\mathrm{C} \omega}{2 \mathrm{~K}}
$$

where $\mathrm{K}$ and $\mathrm{C}$ are the spring and damping coefficients respectively, and $\omega$ is the excitation frequency of the tests. The damper coefficient $\mathrm{C}$ is determined by (see Monti et al. [12])

$$
\mathrm{C}=\frac{\mathrm{E}_{\mathrm{w}}}{\pi \omega \mathrm{d}_{\max }^{2}}
$$




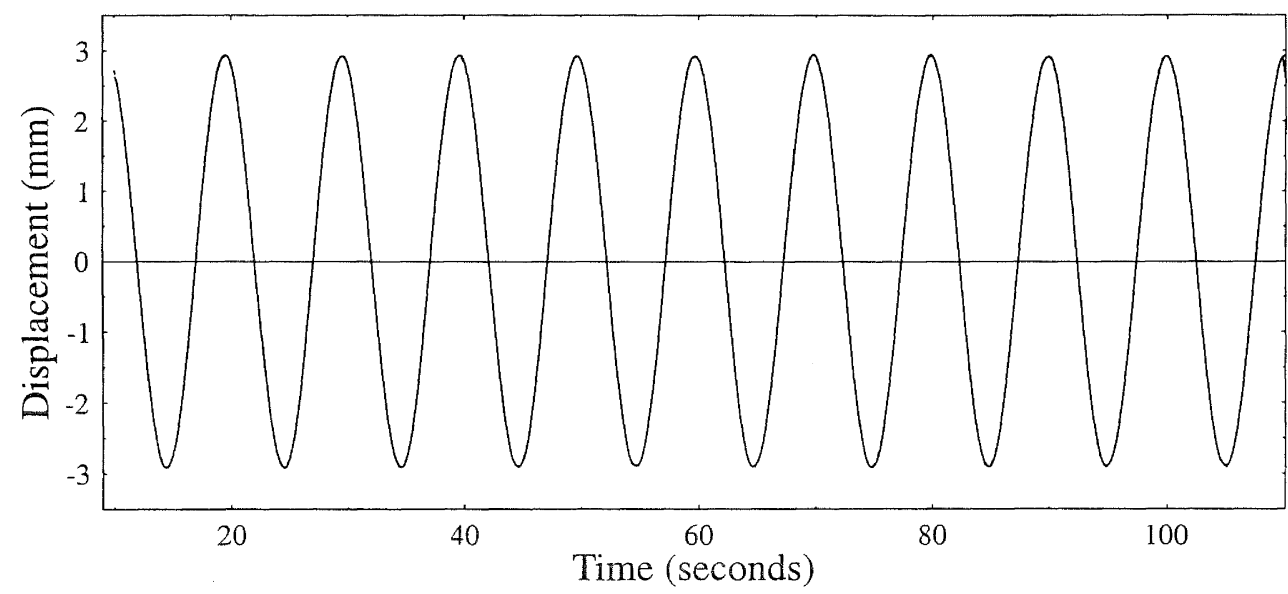

(a)

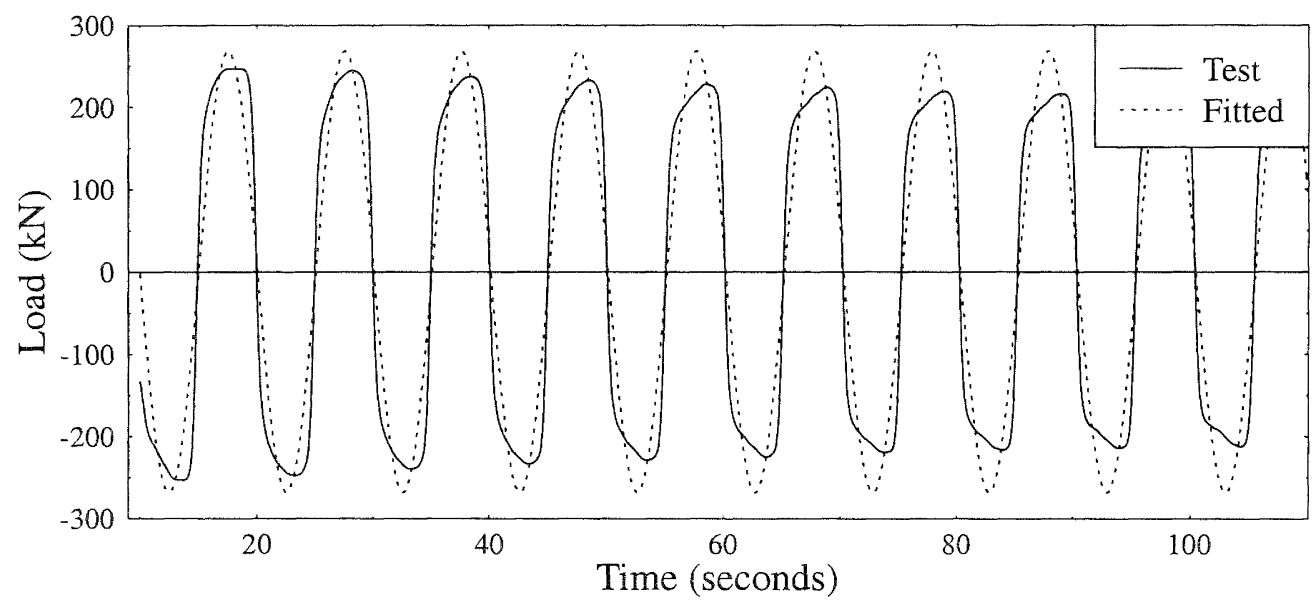

(b)

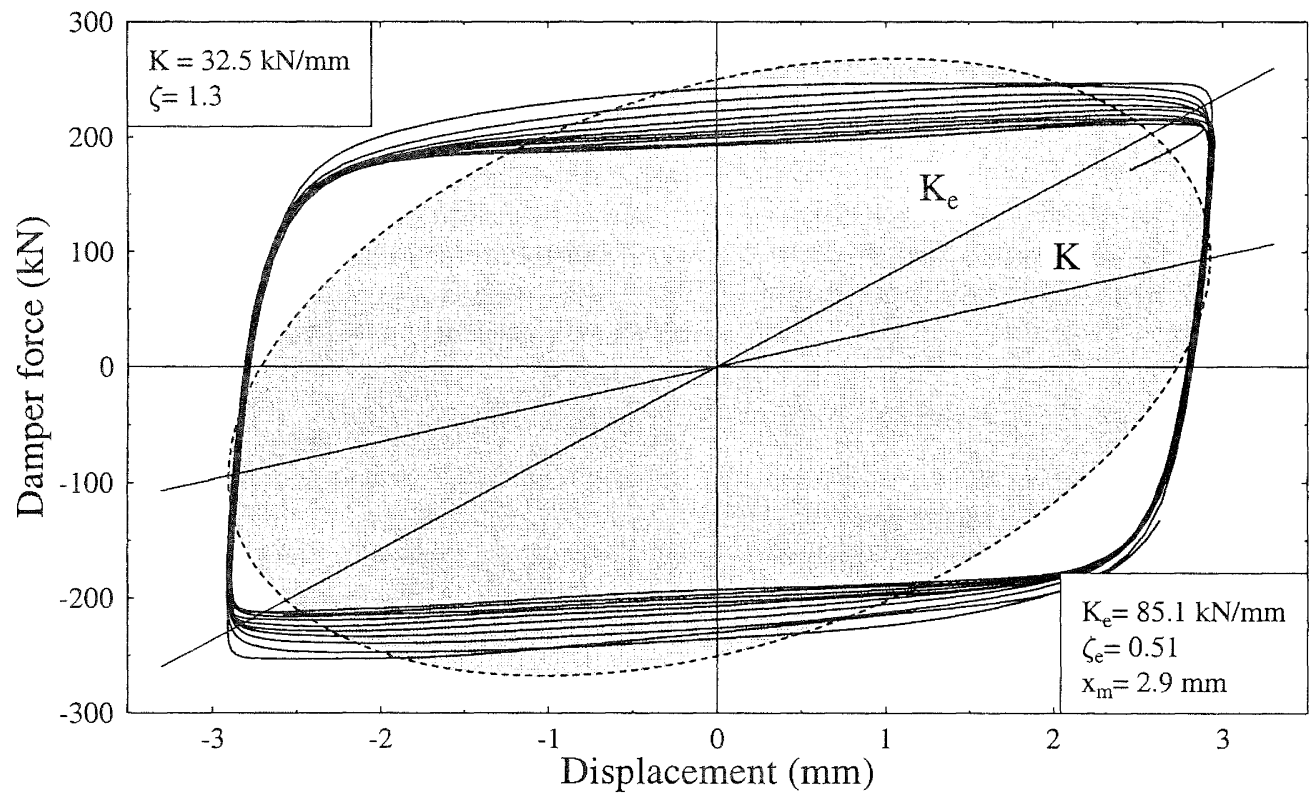

(c)

Figure 3: Results of a test and the fitted model parameters. The shaded area is the hysteresis loop predicted by the model parameters. 
where $E_{\mathrm{W}}$ is the average energy dissipated by the damper per cycle and $d_{\max }$ is the displacement amplitude. It can then be seen that $\zeta$ is independent of frequency for PVDs because $\mathrm{C}$ is inversely proportional to $\omega$.

Using the secant stiffness $\mathrm{K}_{\mathrm{e}}$, the equivalent viscous damping ratio defined by Skinner et al. [1] can be found from

$$
\zeta_{\mathrm{e}}=\frac{\mathrm{E}_{\mathrm{w}}}{2 \pi \mathrm{K}_{\mathrm{e}} \mathrm{d}_{\max }^{2}}
$$

Equation (3) can also be derived from Equation (1) replacing $\mathrm{K}$ with $\mathrm{K}_{\mathrm{e}}$ and Equation (2).

Parameters $\mathrm{K}, \mathrm{K}_{\mathrm{e}}, \zeta$ and $\zeta_{\mathrm{e}}$ are dependent on displacement amplitudes and therefore are functions of the peak displacement of the steady-state deformation time-history. Figure 4 shows the hysteresis loops of a PVD for various peak displacements and the equivalent hysteresis loops of the linear spring-damper model (the shaded areas). It can be seen that at a peak displacement of $0.1 \mathrm{~mm}$, a significant amount of energy is dissipated by the damper, and that at a peak displacement of $1.0 \mathrm{~mm}$, the damper behaviour is close to that of a bi-linear model. At a peak displacement of about $5 \mathrm{~mm}$, the hysteresis loops of the damper are almost perfectly bi-linear with a postyield stiffness of less than $1 \%$ of the initial stiffness.

Damping ratios and normalized stiffness coefficients are shown in Figure 5 where $K_{\max }$ is the PVD stiffness at a very small displacement $(<0.005 \mathrm{~mm})$. It is apparent that the variations of these parameters are very similar in character to those of clays or sands. For this particular PVD, the damping ratio reaches its maximum value at about $1 \mathrm{~mm}$ of peak displacement and the spring coefficient is less than $10 \%$ of the initial elastic stiffness at this amplitude of displacement.

(b) Bi-linear spring model

A bi-linear model is defined by its initial stiffness $\mathrm{K}_{0}$, nominal yield force $F_{y}$ and the post-yield stiffness ratio $\alpha$ (the ratio of the post-yield stiffness to the initial stiffness), as shown in Figure 6(a). These parameters can be derived from the experimental data using a method similar to that given by Monti et al. [12]. It is essentially a least-squares approach which minimizes the difference between the predicted and the measured damper forces. The theoretical hysteresis loops are compared to those of the experimental data in Figure 6. Figure 6 shows that bi-linear models with displacement-dependent parameters can approximate the experimental loops well for a wide range of peak displacements $(0.1-5 \mathrm{~mm})$. Variations of the initial stiffness $K_{0}$, the stiffness ratio $\alpha$ and the nominal yielding force $F_{y}$ with peak displacement are shown in Figure 7. The initial stiffness and the nominal yielding force change little for peak displacement larger than $1 \mathrm{~mm}$ and can be taken approximately as constants. The post-yield stiffness ratio varies from about $15 \%$ at a peak displacement of $0.1 \mathrm{~mm}$ to about $0.5 \%$ at a peak displacement of $5 \mathrm{~mm}$. At large displacements, the hysteresis loop of the PVD is very close to that of a bi-linear model. The damping ratio of a bi-linear model can be written as [1],

$$
\zeta_{\mathrm{e}}=\frac{2}{\pi}\left[\frac{1}{1+(\mu-1) \alpha}-\frac{1}{\mu}\right]
$$

where $\mu$ is the ductility of the PVD, i.e., the ratio of the peak displacement $d_{m}$ to the nominal yielding displacement $F_{y} / K_{0}$. Equation (4) shows that a small post-yield stiffness ratio $\alpha$ will reduce the equivalent damping ratio by a significant amount. For example, for a peak displacement of $5 \mathrm{~mm}, \mu=50$ and $\alpha=$ $0.5 \%, \zeta_{\mathrm{e}}=50 \%$ will be obtained rather than $\zeta_{\mathrm{e}}=62 \%$ for the case of $\alpha=0.0$. The damping ratio $\zeta_{\mathrm{e}} \cong 50 \%$ at a large peak displacement $(>1 \mathrm{~mm}$ ) agrees with values in Figure 5, when a PVD undergoes a steady-state deformation, and that the hysteresis loops can be approximately modelled by a bi-linear spring. Note that all the experimental data has been obtained from steady-state testing.

\section{(c) Curvilinear models}

Hyperbolic and Ramberg-Osgood, multi-surface non-linear models are used to describe the hysteresis behaviour of the PVD. The hyperbolic model relating PVD force $F$ and displacement $u$ is defined by (Ishihara page 35 [13])

$$
\frac{F}{F_{y}}=\frac{u / u_{y}}{1+u / u_{y}}
$$

where $F_{y}$ is a nominal yielding force and $u_{y}$ is a nominal yielding displacement. The equivalent damping ratio for this model is given by (Ishihara page 35 [13])

$$
\zeta_{\mathrm{e}}=\frac{4}{\pi}\left[1+\frac{1}{\mathrm{u} / \mathrm{u}_{\mathrm{y}}}\right]\left[1-\frac{\ln \left(1+\mathrm{u} / \mathrm{u}_{\mathrm{y}}\right)}{\mathrm{u} / \mathrm{u}_{\mathrm{y}}}\right]-\frac{2}{\pi}(6)
$$

The Ramberg-Osgood model is defined by (Ishihara page 38 [13])

$$
\frac{\mathrm{F}}{\mathrm{F}_{\mathrm{y}}}=\frac{\mathrm{u} / \mathrm{u}_{\mathrm{y}}}{1+\beta\left|\mathrm{F} / \mathrm{F}_{\mathrm{y}}\right|^{\mathrm{r}-1}}
$$

where $\beta$ and $\mathrm{r}$ are parameters determined from experimental data. The equivalent damping ratio is given by (Ishihara page 38 [13])

$$
\zeta_{\mathrm{e}}=\frac{2}{\pi} \frac{\mathrm{r}-1}{\mathrm{r}+1}\left(1-\frac{\mathrm{F}}{\mathrm{F}_{\mathrm{y}}} \frac{\mathrm{u}_{\mathrm{y}}}{\mathrm{u}}\right)
$$



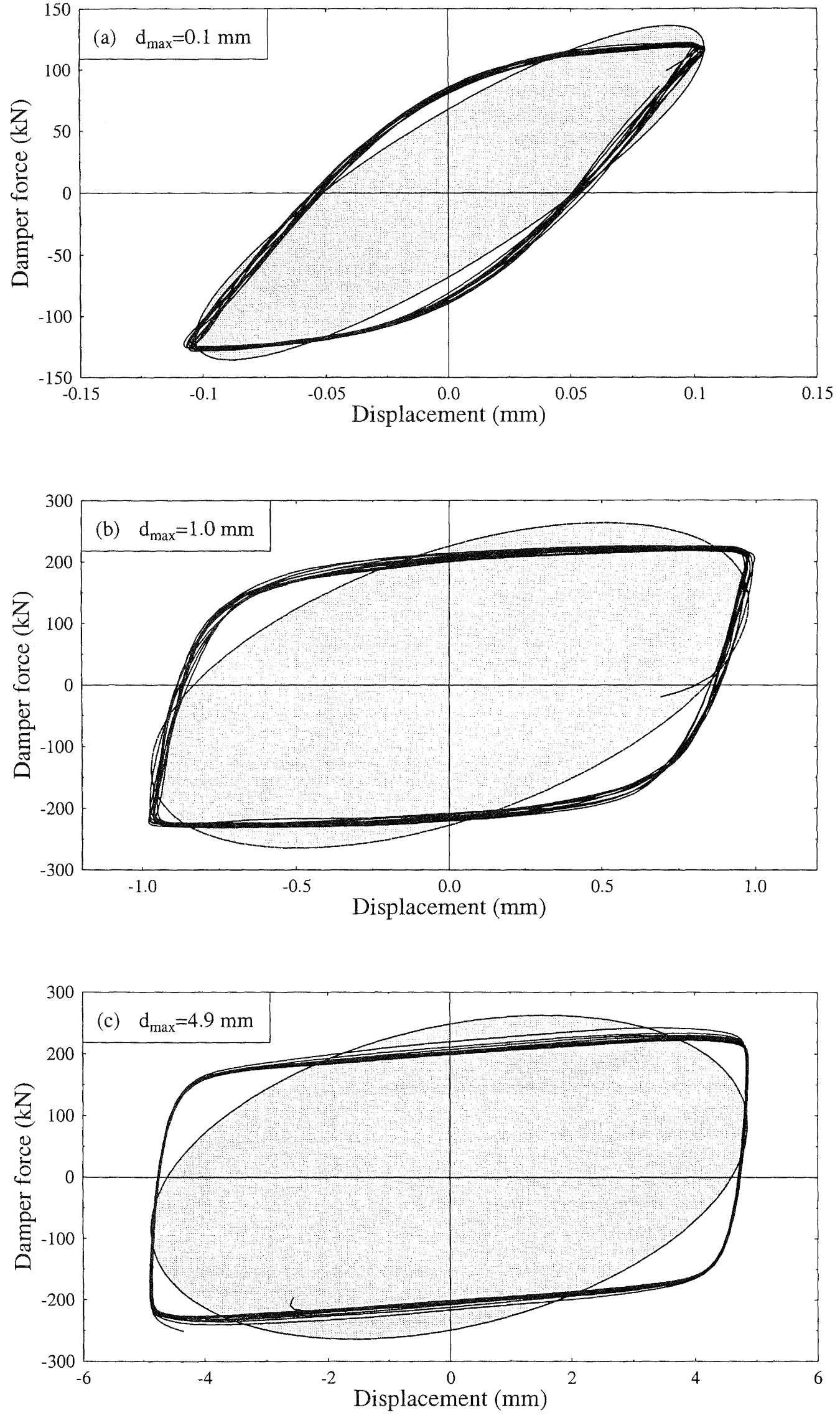

Figure 4: Hysteresis loops of the PVD and its linear-spring-damper model (shaded). 

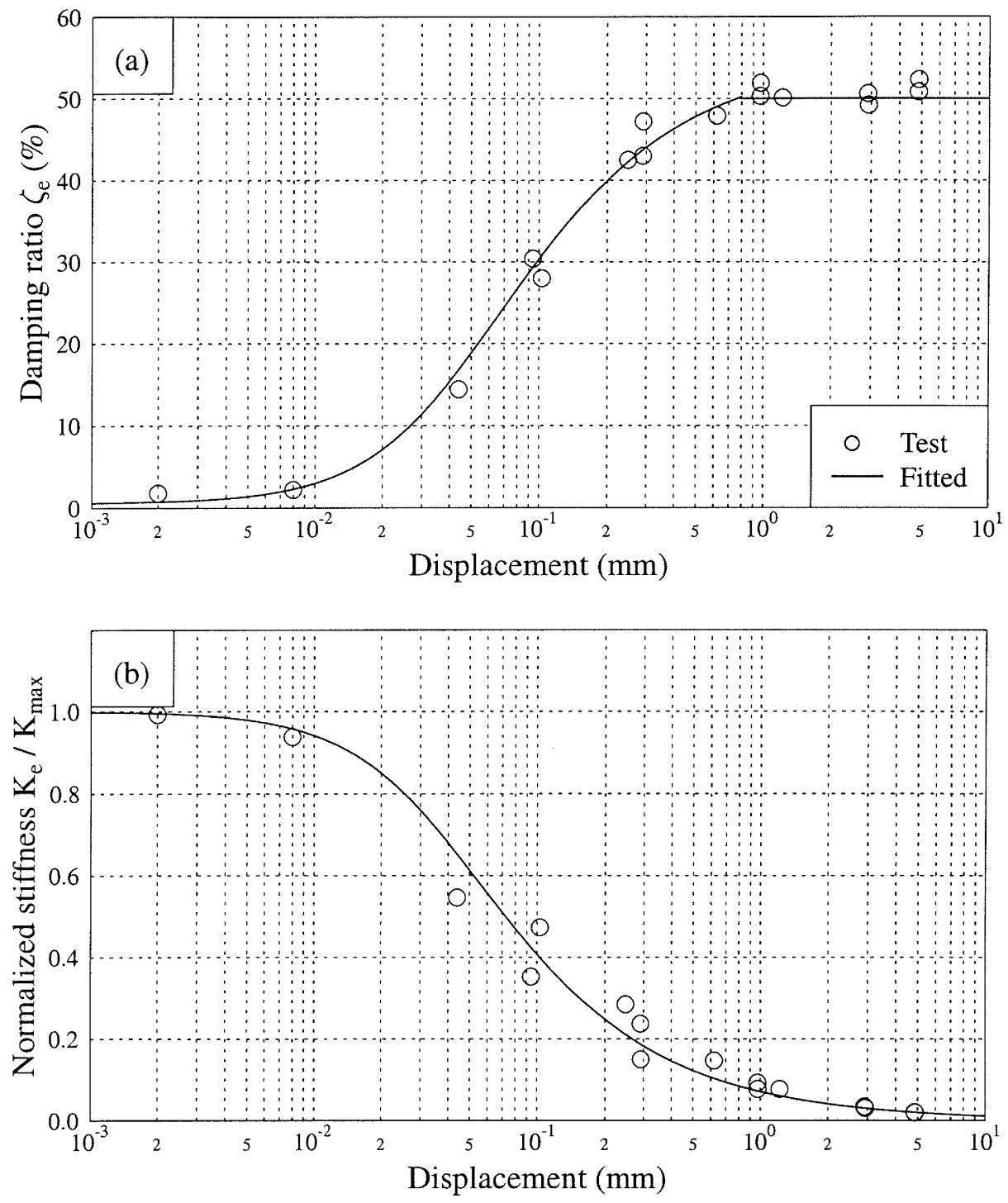

Figure 5: Variation of (a) damping ratio and (b) normalised stiffness coefficient with peak displacement $d_{\text {max }}$. The solid line indicates possible curves for determining the parameter values for a given peak damper displacement.

Multi-surface plasticity models of Iwan [14] use a series of elasto-plastic elements connected in parallel and can also be used to describe non-linear behaviour of PVDs. The equivalent damping ratio of each elasto-plastic element can be obtained from Equation (3) by setting $\alpha=0$, and the total damping ratio can be obtained by summing up all the damping forces from yielded elements at a given amplitude of displacement.

The most important property of the PVD is the amount of damping it can provide. In most computer programs, however, hysteresis loops or the stiffness will be explicitly defined while the amount of damping is indirectly defined by the hysteresis loop. To evaluate each model, its parameters will be selected to match the spring coefficients derived from the experimental data and the damping ratios will then be used to judge the merit of the model. By selecting $\mathrm{u}_{\mathrm{y}}=0.071 \mathrm{~mm}$ and $\mathrm{F}_{\mathrm{y}}=178 \mathrm{kN}$ for the hyperbolic model and $\beta=50, \mathrm{r}=2.9, \mathrm{u}_{\mathrm{y}}=0.25 \mathrm{~mm}$ and $\mathrm{F}_{\mathrm{y}}=$
$625 \mathrm{kN}$ for the Ramberg-Osgood model, the predicted spring and equivalent damping coefficients are compared with those derived from the experimental data in Figure 8. By using 20 elasto-plastic elements, equivalent damping ratios were also evaluated from multi-surface plasticity models. Figure 8 shows that all models fit the spring coefficient reasonably well, but at large displacements the Ramberg-Osgood model produces a much smaller equivalent damping ratio than that derived from the experimental data. The damping ratio of the hyperbolic model is significantly smaller than that derived from the experimental data at a peak displacement less than $1 \mathrm{~mm}$ and much larger than the experimental results at peak displacement above $2 \mathrm{~mm}$. At peak displacements between $0.1-10 \mathrm{~mm}$, the multi-surface model produces damping ratios between those derived from experimental data and those of the RambergOsgood model. The trend of Figure 8 at large peak displacements indicates that the damping ratio derived from the 

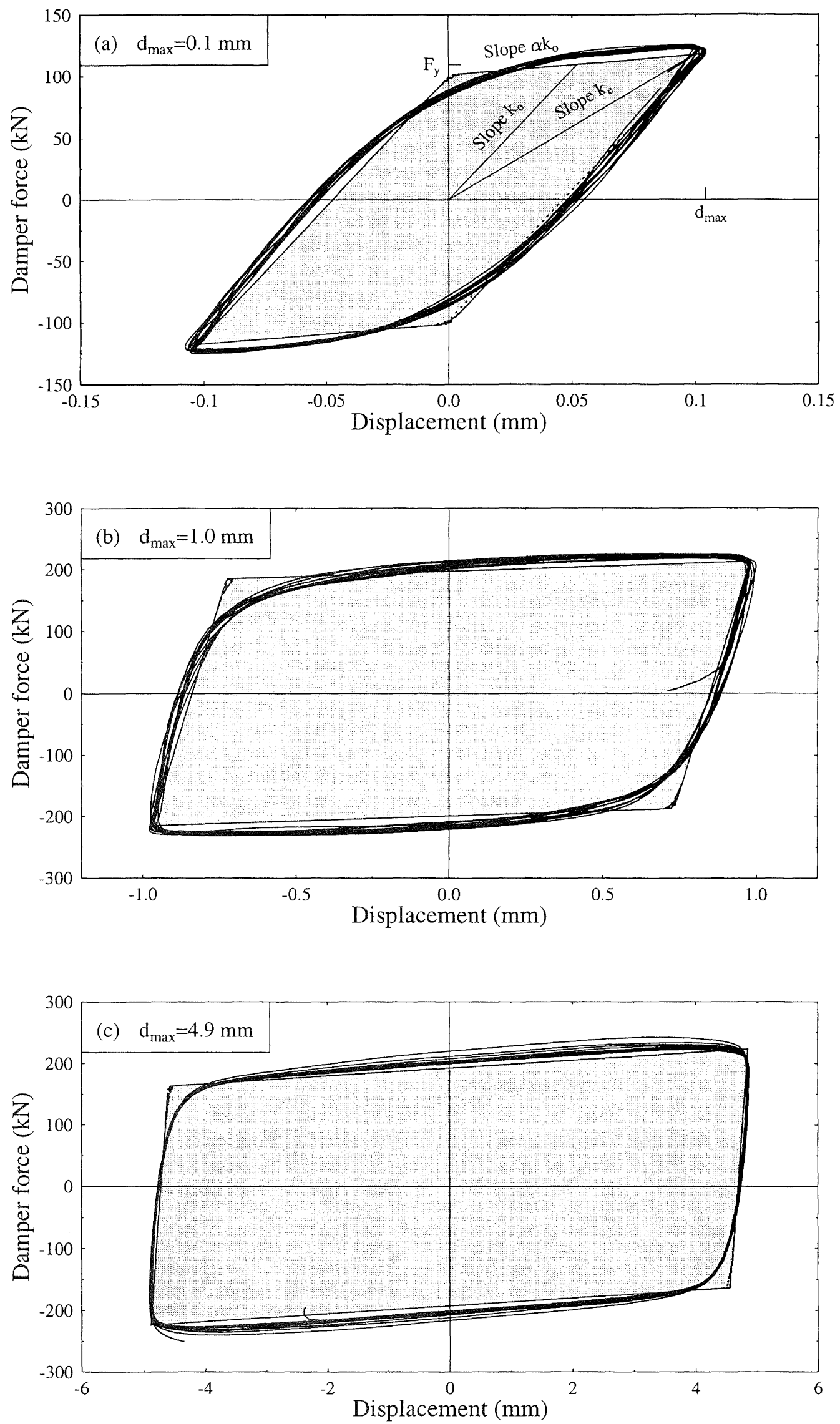

Figure 6: Hysteresis loops of the PVD and its bilinear-spring model (shaded). 

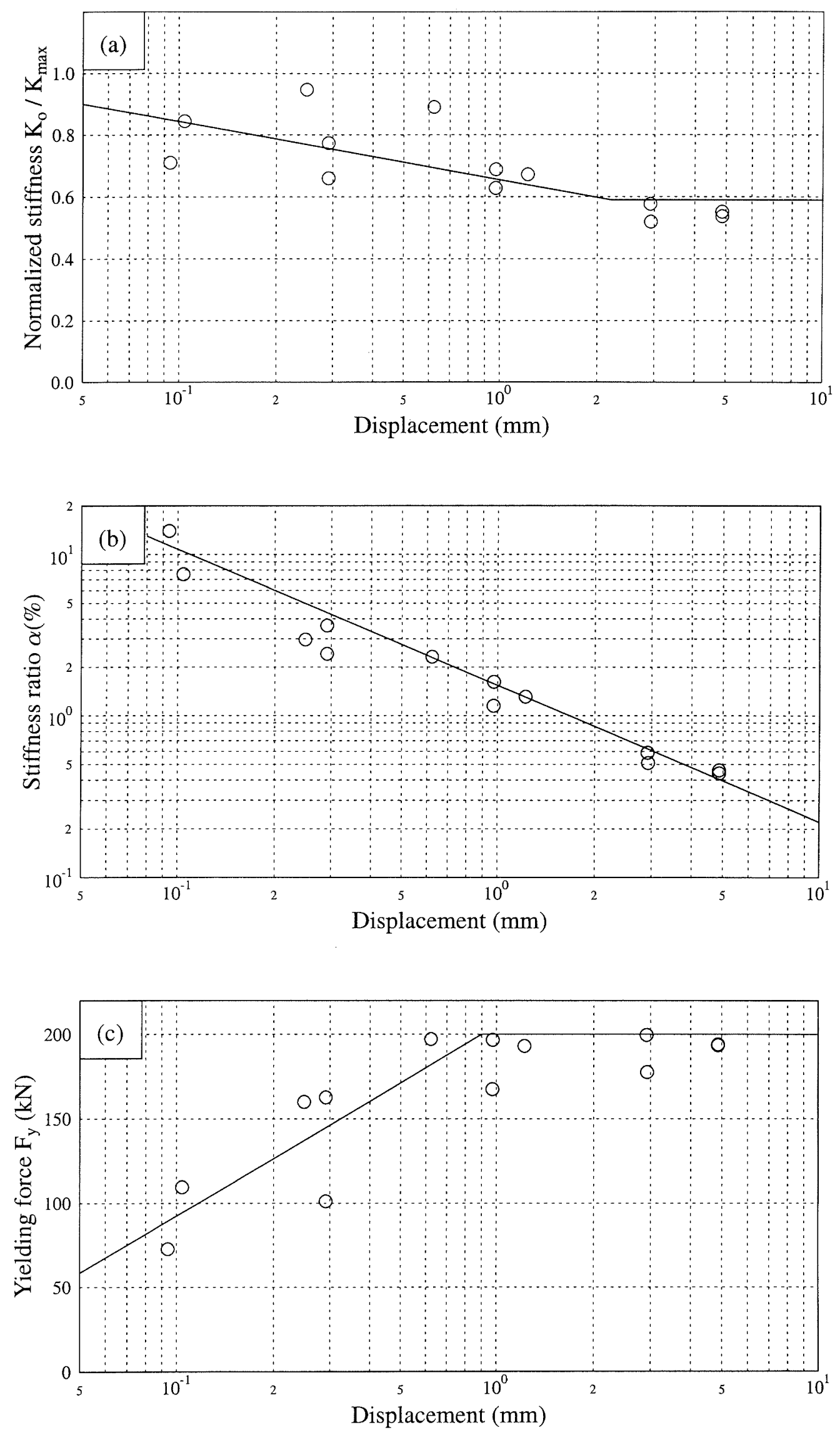

Figure 7: Variation of (a) normalised stiffness; (b) yielding stiffness ratio and (c) nominal yielding force with peak displacement $d_{\text {max }}$ The solid lines indicate possible curves for interpolation. 

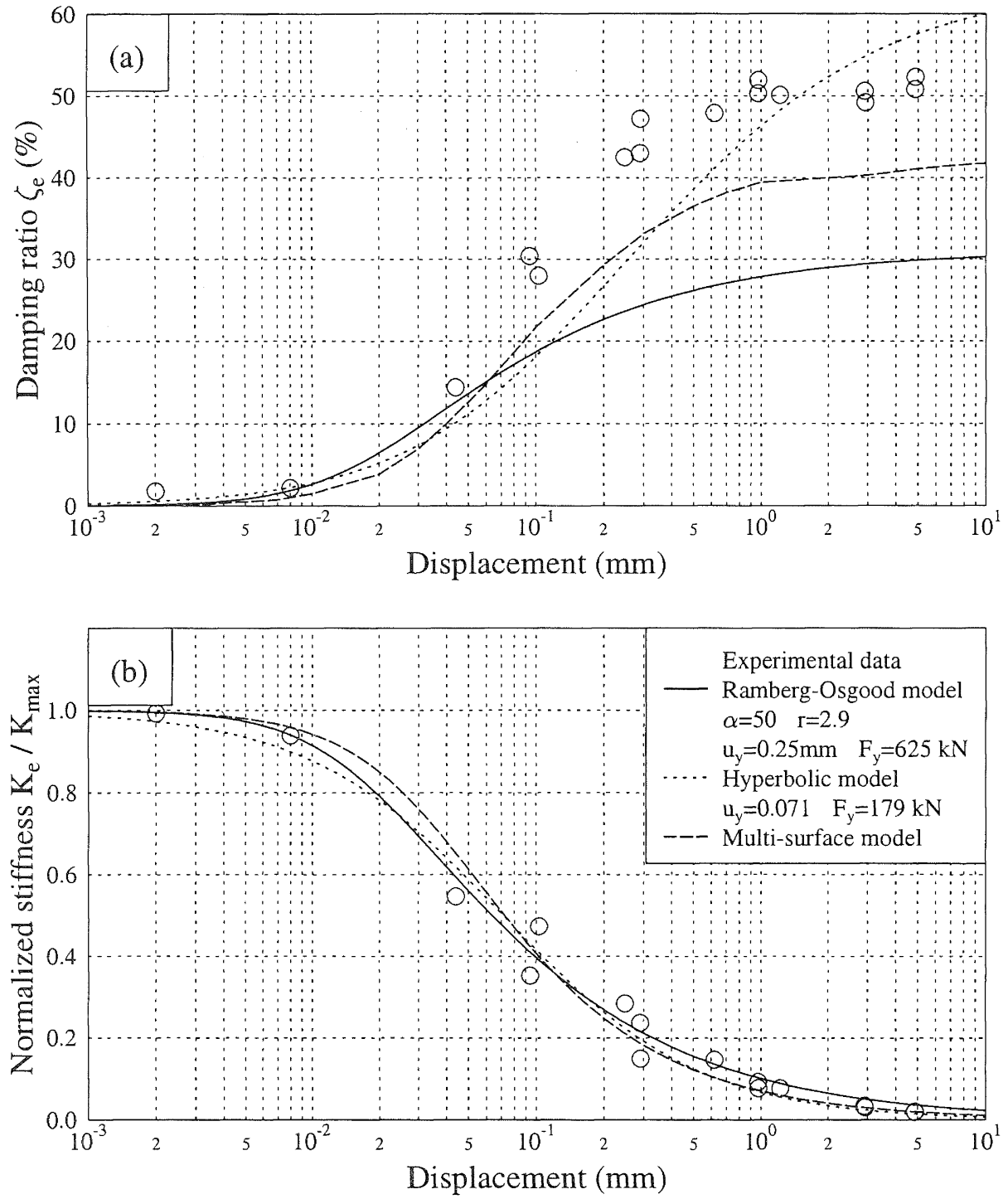

Figure 8: Comparison of (a) damping ratios and (b) normalised stiffness derived from experimental data and those derived from hyperbolic, Ramberg-Osgood and multi-surface nonlinear models.

experimental data is close to that of a bi-linear model (Equation (4), about $\zeta_{\mathrm{e}}=50 \%$ at large displacements, see also Figure 3 ), and that the damping ratio of the hyperbolic model is close to that of an elasto-plastic model $\left(\zeta_{\mathrm{e}}=63.7 \%\right.$ at very large peak displacements). The discrepancy in predicted equivalent damping ratios is possibly the result of the particular loading and unloading rules adopted by these non-linear models, because the rules do not entirely reflect the hysteretic behaviour of the PVD. Intuitively, a non-linear model should reproduce, as closely as possible, the equivalent damping ratio derived from experimental data while predicting only approximately the spring coefficient, because it is damping that a PVD is required to provide to a structure. The stiffness of the PVD will change the dynamic characteristics of a structure but the extent of the change would be very small. Therefore, the modelling of PVD stiffness is less important than the modelling of its damping properties. When the damper displacement is likely to be much larger than the nominal yielding displacements of the PVDs, it is possibly desirable to use bilinear models for PVDs installed in a structure, as the bi-linear model with suitably selected parameters produces an amount of damping similar to that obtained from the experimental data at large damper displacements. The results of these analyses, however, need to be confirmed by non-linear structural modelling. 


\section{EXPERIMENTAL RESULTS AFTER FATIGUE TESTS}

To examine effects of the fatigue tests on the dynamic parameters of the PVD, experiments were conducted again after the PVD had been subjected to 144000 cycles with a displacement amplitude of $2 \mathrm{~mm}$. The maximum loading frequency was $0.5 \mathrm{~Hz}$ for a displacement amplitude $1.0 \mathrm{~mm}$ or less and the loading frequency decreased to $0.01 \mathrm{~Hz}$ for large displacements because of limited loading capacity of the testing machine. The hysteresis loops are shown in Figure 9 and 10. Figure 9(c) shows that the hysteresis behaviour of the PVD is almost independent of loading frequency. The damping ratios and the normalised stiffness coefficients are shown in Figure 11. Compared with the results before the fatigue tests, there are some changes in the dynamic parameters for the PVD. The damping ratios for small peak displacements (less than $1.5 \mathrm{~mm}$ ) are less than those derived from the experimental results before the fatigue test and for large peak displacements they are larger than those before the fatigue test. These changes indicate that the nominal yield force of the PVD increases by about $10-15 \%$ after the fatigue test. The increase of the nominal yield force of the PVD gradually appeared only after about 120000 cycles during the fatigue tests and became stable at about 130000 cycles. Changes for the normalised stiffness coefficients, however, are small, especially at large displacements.

These results indicate that the PVD has performed extremely well under a very large number of loading cycles and its long term stability can be assured. The energy dissipation capacity of the PVD increases slightly after 144000 cycles of fatigue test.

\section{AN ILLUSTRATIVE EXAMPLE}

Two identical 6-storey reinforced concrete moment resisting frames connected by rigid links at each floor, as shown in Figure 2, are used to demonstrate the effectiveness of PVDs. The design parameters of the frame were provided by the Department of Civil Engineering, University of Canterbury. The dimension of the beams is $600 \times 350 \mathrm{~mm}$ for levels $1-3$ and $550 \times 350 \mathrm{~mm}$ for levels $4-6$. The dimension of the interior columns is $500 \times 450 \mathrm{~mm}$ for levels $1-3$ and $450 \times 450 \mathrm{~mm}$ for levels 4-6. The dimension of the exterior columns is $550 \times 550$ $\mathrm{mm}$ for levels $1-3$ and $500 \times 500 \mathrm{~mm}$ for levels $4-6$. The design seismic coefficient for the structure was 0.082 which is similar to $1 / 6$ of the elastic spectral acceleration value of the El Centro 1940 NO0E component at a period about 0.9-1.0 seconds. If the design ductility factor is assumed to be 6 , a minimum value specified for reinforced concrete moment resisting frames by the current New Zealand loadings standard [15], the design seismic coefficient used for this frame corresponds to the level of shaking produced by the unscaled El Centro 1940 record (NOOE component).

The first elastic modal frequency of the frame was $1.1 \mathrm{~Hz}$ and a damping ratio of critical of $3 \%$ and $5 \%$ were assumed for the first and the second modes. The rigid links indicate that PVDs are installed in every second frame of the building in the direction perpendicular to the earthquake excitation considered. In a real situation, a frame with PVDs is likely to have different design parameters from the frame without PVD. The northsouth component of the $1940 \mathrm{El}$ Centro acceleration record was used as the excitation and the length of the record used was 20 seconds. PVDs with a design yielding force of $200 \mathrm{kN}$ were assumed for the bottom three storeys and $100 \mathrm{kN}$ for the top three storeys.

PVDs provide added damping and added stiffness to a structure, because of the large stiffness of the PVDs. The added stiffness can be an advantage or disadvantage for the maximum response of a structure, depending on the frequency content of earthquake excitation and modal frequencies of the structure. Thus a comparison of the maximum response values for a structure with and without PVDs under an earthquake excitation will not fully reflect the effectiveness of PVDs. In this paper, the approach adopted was to compare the equivalent first modal damping ratios for a structure with and without PVDs.

Non-linear deformation through plastic hinging was allowed at the bottom of the ground floor columns and at the ends of all beams, and bi-linear models were used to model these plastic hinges. PVDs were also modelled as bi-linear models defined by parameters shown in Figure 6(a) and Figure 7. Because of non-linear deformation of the structure and the PVDs, direct evaluation of modal damping ratio was not appropriate. Instead, the following approach was taken.

The total acceleration responses at the 2 nd, 4 th and 6 th floors of the structure under a scaled earthquake excitation were evaluated and used to estimate equivalent viscous modal damping ratios by using a systems identification method [16]. In the systems identification method, an elastic model was assumed and the total floor responses were matched by the modal responses. The error between the frame non-linear responses and the elastic modal responses was minimised by systematically selecting appropriate values for elastic modal frequencies, modal damping ratios and effective modal participation factors [16]. This approach is consistent with the displacement-based design concept, advocated by Priestley [17], where an elastic structural model based on secant stiffness and equivalent viscous damping ratios of all structural members is used. This approach has also been used in the design of non-linear base-isolated structures $[18,19]$, and the design of structures installed with frequency-dependent viscoelastic dampers [20], and it has been shown to give satisfactory results.

The equivalent viscous damping ratios evaluated can then be plotted as functions of the peak roof displacement. The variation of the damping ratios with peak roof displacement will be much less dependent on the characteristics of the ground motion than the peak roof displacement itself.

The initial stiffness of the PVDs is quite high. For example, the initial stiffness at very small displacement for a PVD with a design yielding force of $200 \mathrm{kN}$ and a maximum design displacement of $10 \mathrm{~mm}$ is $2500 \mathrm{MN} / \mathrm{m}$ [12]. As shown by Monti et al. [9], to achieve a high energy absorption efficiency at small damper displacements, ideally the structural connection stiffness for a PVD installation should be close to the maximum stiffness of the PVD. For a structural configuration as shown in Figure 2, such a high value of stiffness for the bracing member is impractical and expensive. 

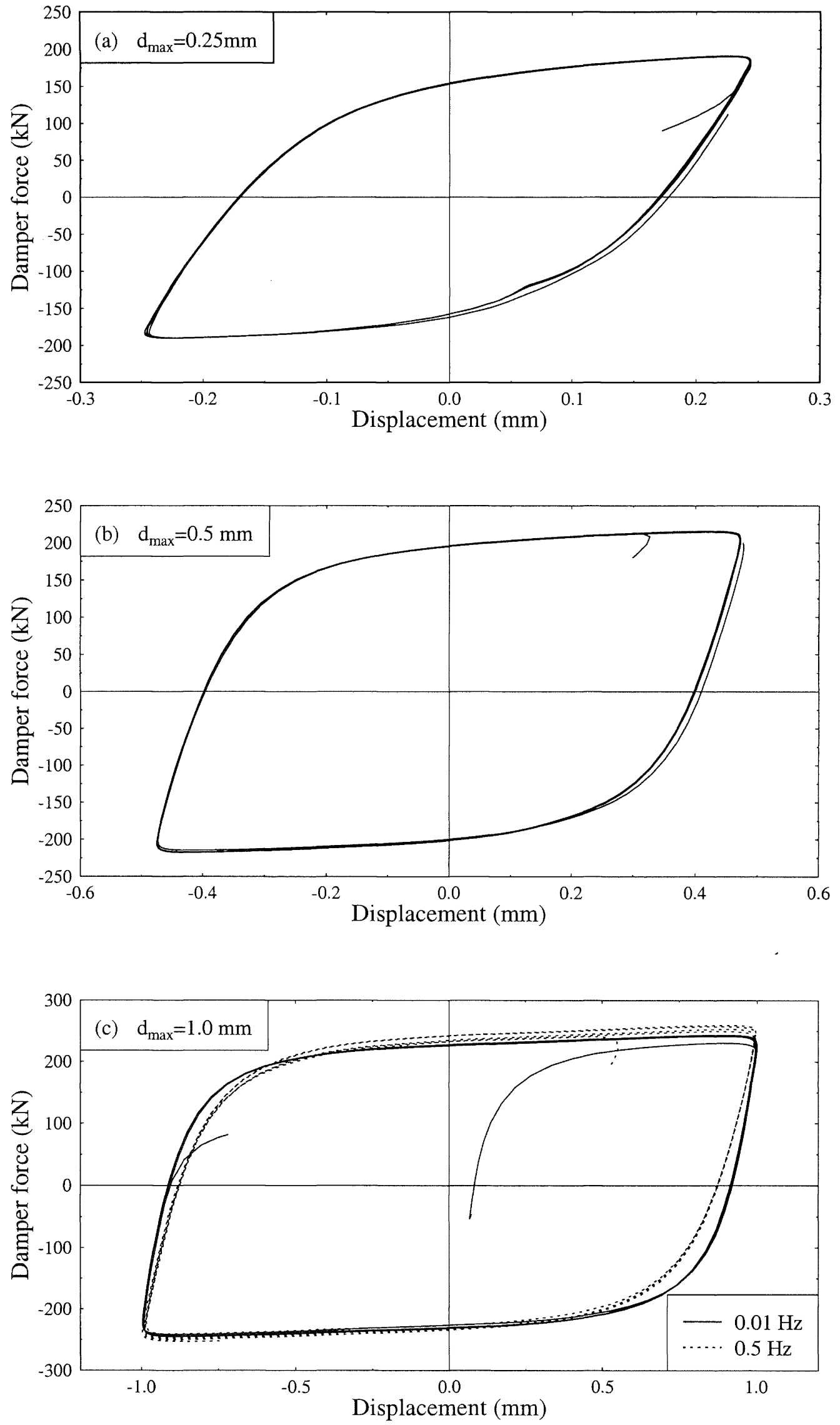

Figure 9: Hysteresis loops of the PVD after 144000 cycle tests. 

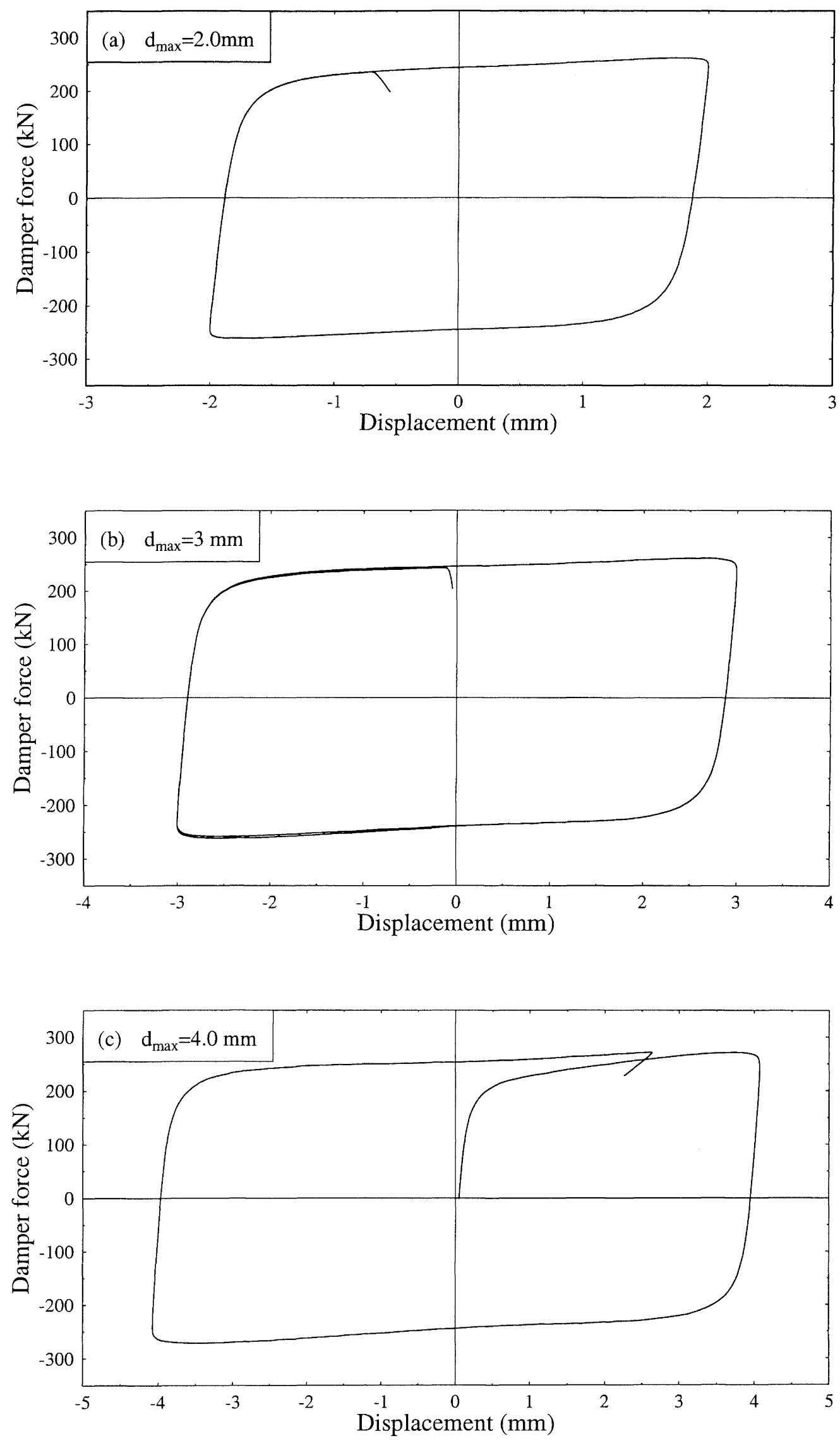

Figure 10: Hysteresis loops of the PVD after 144000 cycles. 

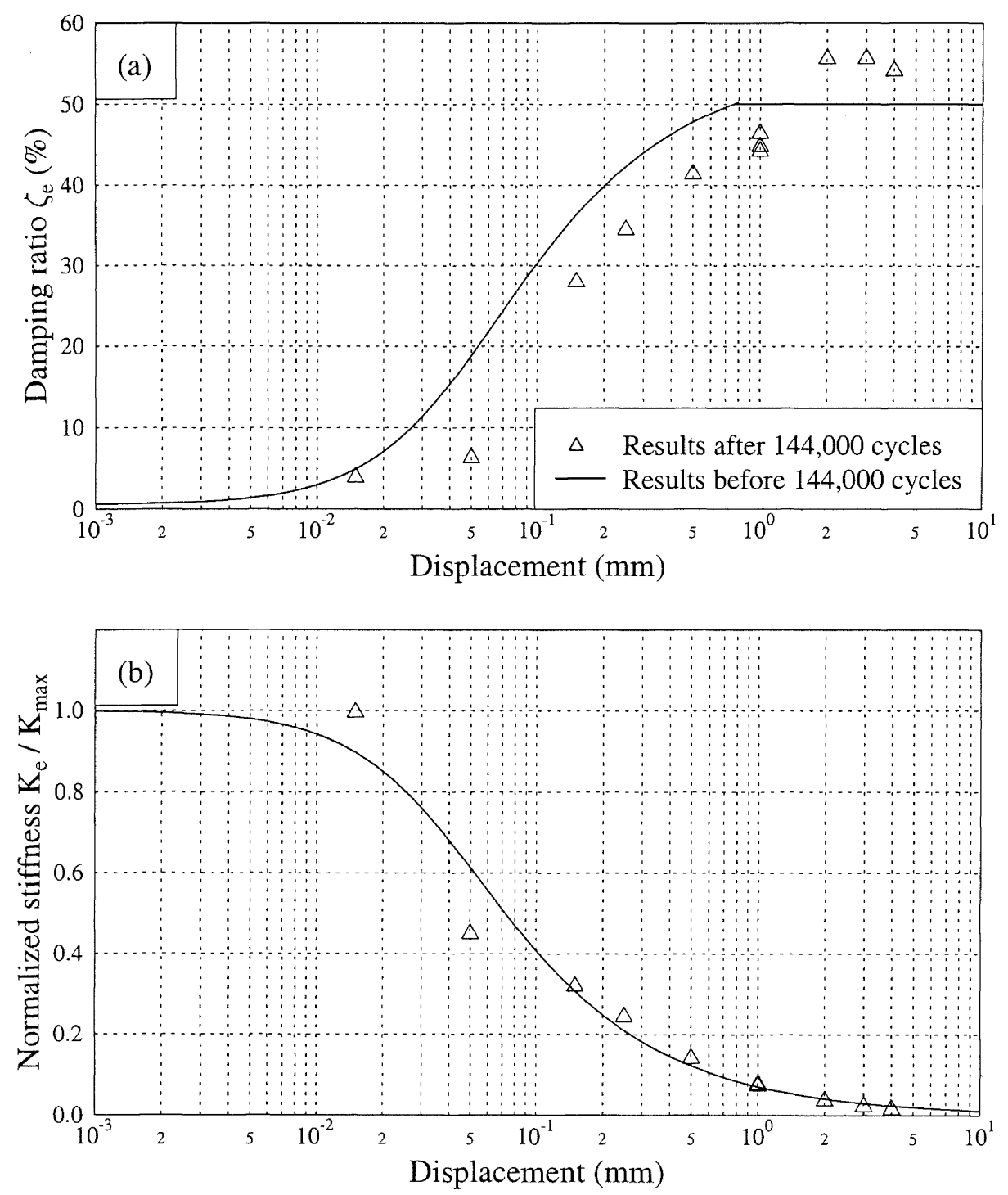

Figure 11: Variation of (a) damping ratio and (b) normalised stiffness with peak displacement $d_{\text {max }}$ for the tests after 144000 cycles.

The bracing members here were designed for carrying $300 \mathrm{kN}$ compression force and the member size was largely controlled by the maximum buckling load, giving a gross cross section area of $2810 \mathrm{~mm}^{2}$. Because the maximum damper displacement required in this example is about $20-25 \mathrm{~mm}$, the maximum initial stiffness of the PVDs was taken as 1250 $\mathrm{MN} / \mathrm{m}$, half of the value for the $200 \mathrm{kN}$ PVD presented by Monti et al. [12], based on an assumption that the PVDs for this example would have a total thickness at least twice that of the $200 \mathrm{kN}$ PVD (the maximum initial stiffness can if necessary be one of the design parameter for the PVD). The stiffness of the bracing member would then be $10 \%$ of the maximum initial stiffness of the PVDs and thus the energy absorption capacity is fully employed only at a large damper displacement. The bi-linear parameter variation with damper peak displacement was assumed to be the same as that for the $200 \mathrm{kN}$ PVD shown in Figure 7.

The responses of the structural model were computed by using PC-ANSR [21]. The bi-linear model parameters for the PVDs were determined iteratively but it was found that for most cases the bi-linear parameters were in a range of constant values.

The roof displacement relative to the structure base is shown in Figure 12(a) where the unscaled El Centro 1940 NOOE records was used as the excitation. Figure 12(a) shows that the roof 

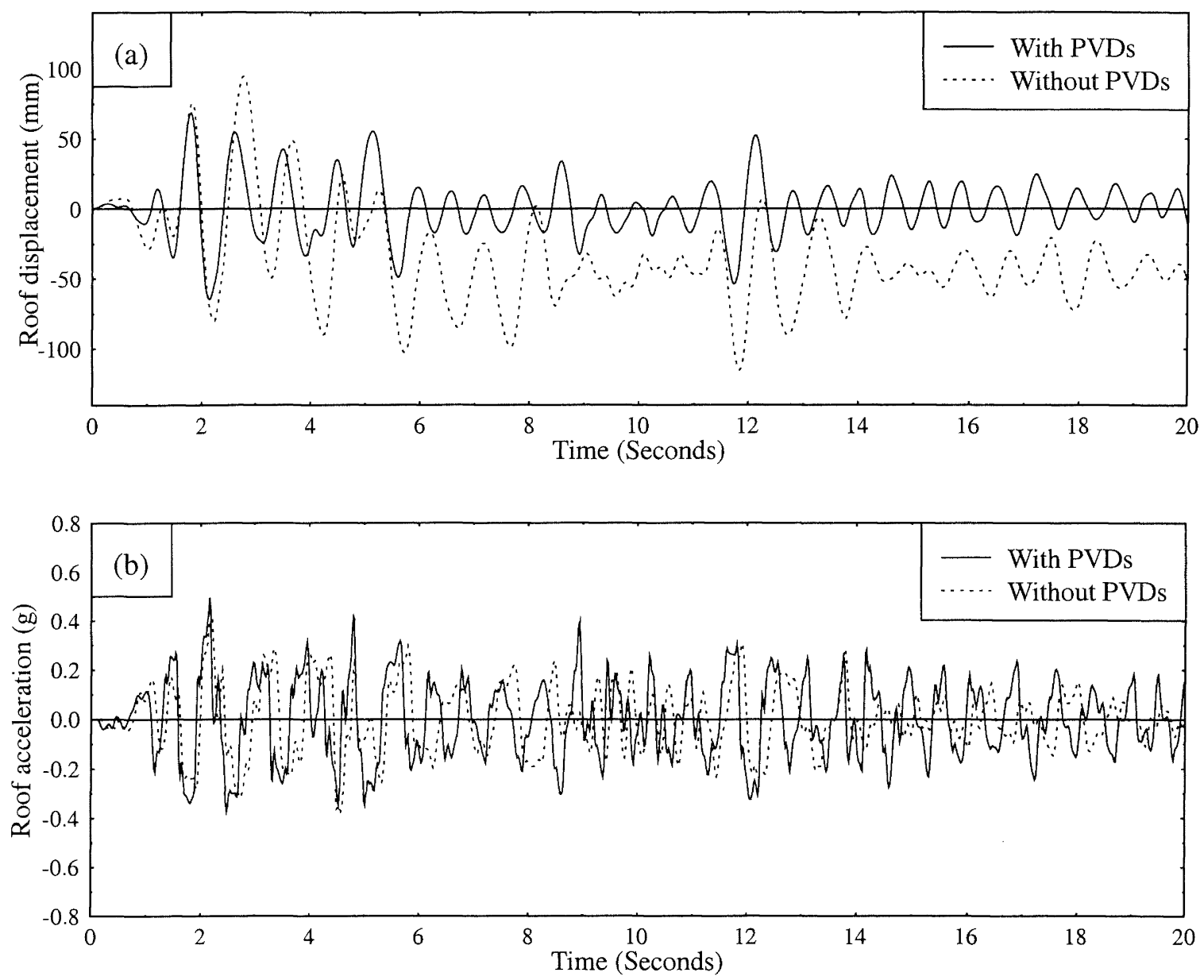

Figure 12: Responses of the frame model shown in Figure 2 with and without PVDs, (a) roof relative displacement and (b) roof total acceleration.

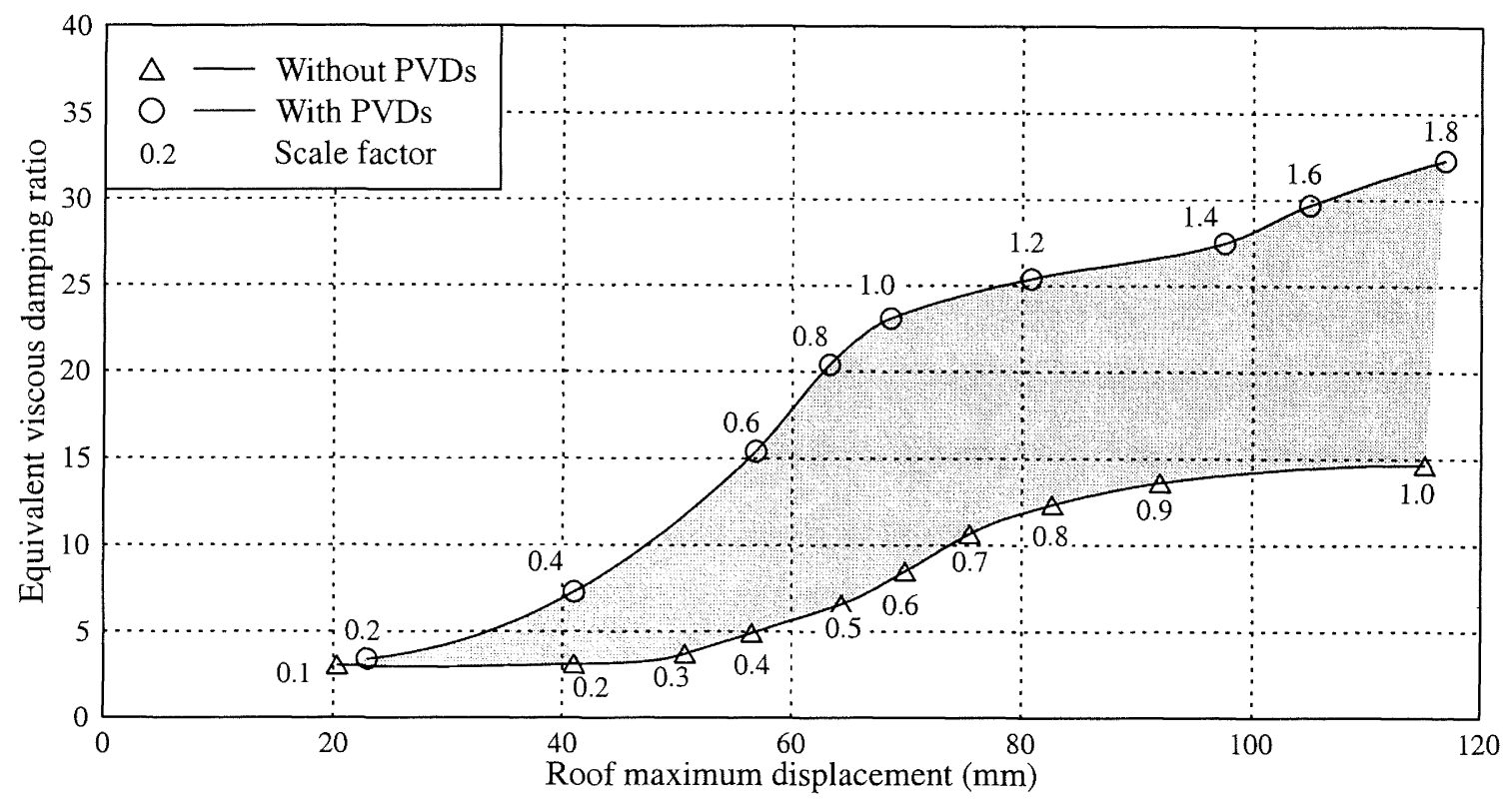

Figure 13: Estimated equivalent viscous damping ratios for the first mode of the numerical model shown in Figure 2 with and without PVDs. The scale factors for the earthquake excitation are also shown for each case. The shaded region indicates the enhancement of damping ratios by PVDs. 
displacement of the structure with PVDs is much smaller than that of the structure without PVDs and that the structure with PVDs has little permanent roof displacement. The maximum inter-storey drift of the structure with PVDs is $17 \mathrm{~mm}$ between level 3 and level 2, considerably smaller than that for the structure without PVDs, $24 \mathrm{~mm}$ between level 1 and the ground floor.

The roof total acceleration responses for the structural models with and without PVDs are shown in Figure 12(b). It can bee seen that the maximum roof total accelerations for the two structures are quite similar. The similar peak acceleration values are possibly caused by the combined effect of added stiffness (increasing acceleration response for the El Centro record) and added damping (decreasing acceleration response) from the PVDs.

The estimated equivalent viscous damping ratios of the first mode for the structure shown in Figure 2 are presented in Figure 13 as functions of peak roof displacements for the cases with and without PVDs. The shaded area indicates the contribution to the structural modal damping from the PVDs. The scale factors for the ground acceleration are also shown in Figure 13.

Figure 13 shows that damping contributed by the PVDs gradually increases from zero at a peak roof displacement of 20 $\mathrm{mm}$ to about $17 \%$ at a peak roof displacement of $115 \mathrm{~mm}$. At a peak roof displacement larger than $60 \mathrm{~mm}$, the damping contribution from PVDs is almost constant. Figure 13 shows that for a scale factor of 0.2 , the peak roof displacement is reduced from $41 \mathrm{~mm}$ for the structure without PVDs to $23 \mathrm{~mm}$ for the structure with PVDs. For a scale factor of 1.0, the peak roof displacement is reduced from $115 \mathrm{~mm}$ to $69 \mathrm{~mm}$. However, for a scale factor of 0.8 , the peak roof displacement is reduced by a relatively small amount, from $83 \mathrm{~mm}$ to 63 $\mathrm{mm}$, indicating that the reduction in peak roof displacement by PVDs depends on the structure modal frequencies and the frequency contents of the ground motion.

Figure 13 also shows that, at a peak roof displacement of about $40 \mathrm{~mm}$, the frame capacity for resisting ground accelerations is enhanced by $100 \%$ (from a scale factor of 0.2 to 0.4 ) by PVDs, assuming that the capacity of a structure can be defined by the maximum allowable roof displacement. At a peak roof displacement of about $115 \mathrm{~mm}$, the frame capacity is increased by $80 \%$. At a peak roof displacement of $80 \mathrm{~mm}$, the earthquake resisting capacity of the frame is enhanced by $50 \%$ by the PVDs, indicating again the dependence on dynamic characteristics of both the structure and ground motions.

The "apparent" first modal frequency of the structure with PVDs is about $1.6 \mathrm{~Hz}$ at a scale factor of 0.2 and gradually decreases to about $1.3 \mathrm{~Hz}$ at a scale factor of 1.8 . The added stiffness from PVDs for this flexible structure is quite significant.

Because a highly non-linear system was approximated by an equivalent linear system, the matching error is inevitably large for high level earthquake excitation. However, the damping ratios estimated by the systems identification match quite well those derived approximately from the transfer functions between the structural responses to the excitation, assuming that the effective modal participation factors [16] do not change significantly from those in elastic cases.

\section{MAIN CONCLUSIONS}

1. A new lead-shear damper, the Penguin Vibration Damper (PVD), behaves as a plastic damping device with design working displacements in the range of 50 micro-metres to $10 \mathrm{~mm}$ for the particular device shown in the present study.

2. The PVD has a simple and compact design and is unlikely to fail by fatigue. It can reliably provide adequate damping to structures having a wide range of fundamental modal periods, including those for which seismic isolation is not appropriate.

3. Model parameters for practical design purposes are derived for a prototype of the PVD, and it has been shown that the PVD provides a significant amount of damping at displacements as small as 50 micrometres. The damper can be well modelled as a spring and a viscous dashpot in parallel. The spring coefficient is very small at operating displacements of the damper, compared to its initial stiffness, while the damping ratio is very large. The damper can also be well modelled by a bi-linear spring with displacement-dependent parameters.

4. The PVD has non-linear hysteresis loops and can be described by non-linear models, such as hyperbolic, Ramberg-Osgood and multi-surface plasticity models. However, care must be taken to ensure that energy dissipation capacity of the PVD is estimated correctly. For earthquake loadings where PVDs are expected to undergo large deformations, it is possibly better to use a bi-linear model with appropriately selected parameters, than to use nonlinear models, because a bi-linear model predicts the equivalent damping accurately at large displacements.

5. The experimental results of the PVD after 144000 cycles of fatigue testing with a peak displacement of $2 \mathrm{~mm}$ show that the energy dissipation capacity of the PVD at large displacements increases slightly. The nominal yielding force also increases by about $10-15 \%$. These changes gradually appeared after about 120000 cycles during the fatigue test and the PVD hysteresis behaviour became very stable after 130000 cycles. 
The model for a 6 storey reinforced concrete moment resisting frame demonstrates the effectiveness of PVDs in reducing structural vibration through hysteretic damping. The damping provided by the PVDs increases from a very small amount at a peak roof displacement of $20 \mathrm{~mm}$ to about $10-15 \%$ at a peak roof displacement of $60 \mathrm{~mm}$ or more. The structural capacity for resisting earthquake ground motions is enhanced by $50-100 \%$ by the PVDs, at a given peak roof displacement, for the example shown in this paper.

\section{ACKNOWLEDGEMENTS}

The authors would like to thank David Dowrick and Jim Cousins for their review of the manuscript, Peter Davenport for assistance in the structural model design and $\mathrm{Xi} \mathrm{Lin}$ and Peter Moss for providing the frame model. The research reported here is supported by Foundation for Research Science and Technology of New Zealand, Contract No. C05405.

\section{REFERENCES}

1. Skinner, R.I., Robinson, W.H. and McVerry, G.H. (1993), An introduction to seismic isolation (3 versions in English, Japanese and Chinese respectively), John Wiley and Sons Ltd, West Sussex, England.

2. Robinson, W.H. (1982), Lead-rubber hysteretic bearings suitable for protecting structures during earthquakes, Earthquake Engineering and Structural Dynamics, 10:593-604.

3. Robinson, W.H. and Greenbank, L.R. (1976), An extrusion energy absorber suitable for the protection of structures during an earthquake, Earthquake Engineering and Structural Dynamics, 4:251-259.

4. Robinson, W.H. (1996), Latest advances in seismic isolation, IIWCEE, CD-ROM paper No. 270, Acapulco, Mexico.

5. Robinson, W.H. (1997), Energy Absorber, International Patent Application PCT/NZ97/003.

6. Monti, M.D., Ferguson, W.G. and Robinson, W.H. (1995), Lead as a Cyclic Motion Damper, NZNSEE Pacific Conference on Earthquake Engineering, 3:323330.

7. Monti, M.D. and Robinson, W.H. (1996), A lead shear damper suitable for reducing the motion induced by wind and earthquake, 11WCEE, CD-ROM Paper No. 271, Acapulco, Mexico.

8. Scawthorn, C., Kato, B. and Lu, L.W. (1995), Criteria and loading, Fifth World Congress on Habitat and the High-Rise, 839-1150.
9. Monti, M.D., Gannon, C.R., Zhao, J.X. and Robinson, W.H., (1998), Development and application of a 100 tonne damper, Proceedings of NZNSEE Annual Conference, Wairakei, March, 90-96.

10. Chang, K.C., Soong, T.T., Oh, S-T. and Lai, M.L., (1992), Effect of ambient temperature on viscoelastically damped structure, Journal of Structural Engineering, ASCE, 118(7):1955-1973.

11. Donazzi, F. (1988), The fatigue life of lead alloy $\mathrm{E}$ as a sheathing material for submarine power cables, IEEE Trans. on Power delivery, 3(1): 69-75.

12. Monti, M.D., Robinson, W.H. and Zhao, J.X. (1997), Reducing motion in slender structures induced by wind and earthquake, Technical Conference and AGM, New Zealand National Society for Earthquake Engineering, Wairakei, New Zealand, 14-16 March 1997, 228-235.

13. Ishihara, K. (1996), Soil behaviour in earthquake geotechnics, Clarendon Press, Oxford

14. Iwan, W.D. (1966), A distributed-element model for hysteresis and its steady-state dynamic responses, Trans. ASME. Journal of Applied Mechanics, 33(4):893-900.

15. NZS 4203:1992, Code of practice for general structural design and design loadings for buildings, Standards New Zealand.

16. McVerry, G. H. (1980), Structural identification in the frequency domain from earthquake records, Earthquake Engineering and Structural Dynamics, 3:161-180.

17. Priestley, M.J.N. (1997), Displacement based seismic assessment of reinforced concrete buildings, Journal of Earthquake Engineering, 1:157-192.

18. Hwang, J.S., Chiou, J.M., Sheng, L.H., and Gates, J.H. (1996), A refined model for base-isolated bridges with bilinear hysteretic bearings, Earthquake Spectra, 12(2):245272.

19. Guide specifications for seismic isolation design (1991), American Association of State Highway and Transportation Official, Washington, D.C.

20. Chang, K.C., Soong, T.T., Lai, M.L. and Nielsen, E.J. (1993), Viscoelastic dampers as energy dissipation devices for seismic application, Earthquake Spectra, 9(3):371-387.

21. Maison, B.F. (1992), PC-ANSR, A general purpose computer program for non-linear static and dynamic analysis of three dimensional finite element structural systems. 